\title{
Nomadic tourism: stakeholder collaboration management for tourism development in Mongolia
}

Damba Gantemur*

Mongolian Tourism Association, Ulaanbaatar, Mongolia

Abstract: This study has been produced for the purpose of furthering the debate on the importance of cultural identities in sustainable development processes by giving special emphasis to stakeholder collaboration management in the tourist industry. Tourism plays a critical role, both in strengthening cultural identity and promoting sustainable development. However, there issues that need to be addressed, such as, how tourism, especially community-based tourism (CBT) could help promote local culture, what is the role of key stakeholders, especially local people's attitude towards sustainable development collaboration. These issues have been considered. So far, CBT is a kind of approach to promote sustainable tourism development, and also to be grounded the local circumstances. In other words, local cultural identity enriches and defines the CBT approach by way of matching local cultural identity and tourism development. Nomadic people are viewed as the key engine of their community, who epitomize the local identity. Finally, I propose "A nomad friendly tourism", or "nomadic tourism" that can be seen as a development concept rather than CBT, and which is the practical tool that maintains the balance between natural and cultural landscape of the Mongols.

Keywords: tourism in Mongolia; stakeholder management position; role of local people; Mongolian cultural landscape; community friendly tourism; nomadic tourism;

\section{INTRODUCTION}

As a country sandwiched between giant neighbors Russia and China, Mongolia was isolated from almost the entire world for nearly 70 years until 1990, when democratic forces in the country put an end to the centralized political system. After the breakdown of the old centralized economy, the government set to implementing sweeping programs of monetary, fiscal and structural reforms designed to reduce the role of the government and to facilitate the rapid development of the private sector.

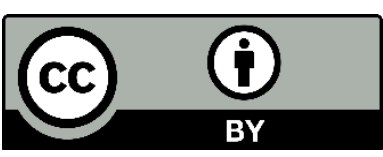

The Author(s). 2020 Open access This article is distributed under the terms of the Creative Commons Attribution 4.0 International License (https://creativecommons.org/licenses/by/4.0/), which permits unrestricted use, distribution, and reproduction in any medium, provided you give appropriate credit to the original author(s) and the source, provide a link to the Creative Commons license, and indicate if changes were made. 
Encountered with stupendous economic and social challenges, the Government put special emphasis on promoting in-bound international tourism as a promising strategy in the national poverty alleviation scheme and in its attempt to reduce the chronic imbalance between national income and expenditures. Following the sharp decline of the world mining commodity market prices, in as much as gold, copper and coal were Mongolia's main income sources, the country began to give priority to fine-cashmere production and tourism.

Since the onset of market economy in the country, private companies have mushroomed. Today, there are more than 620 hotels, 370 tourist camps and lodges, 520 tour operators, all competing in the tourism and hospitality sector. World Tourism Organization reported that international arrivals grew by $5 \%$ in 2018 to reach the USD 1.4 billion mark. At the same time, export earnings generated by tourism have grown to USD 1.7 trillion [5]. In 2019, Mongolia hosted 636.920 foreign visitors and 577,262 foreign tourists, which is by 10.2 percent higher as compared to the previous year. The contribution of travel and tourism to GDP was 3.4\%, and the total revenue generated amounted to USD 607 million [14].

Package tourism with guided and escorted tours is more common in Mongolia, but almost all tour itineraries are conducted in protected areas of the country and as a rule, they must include nomads' daily life program. The duration international tourists stay varies, for example, Western tourists mostly travel between 14 and 21 days throughout the country as a group or as an FIT (free independent traveler). Most programs are special-interest, tailor-made, and outdoor adventure activities. While Asian tourists prefer shorter programs of 5-7 days, which are usually more grouporiented, fully escorted, high service programs.

The major potentials of Mongolia for a successful international tourism development are its beautiful and pristine natural landscape as well as cultural heritage, in particular, pastoral nomadic tradition on the background of modern development. Majority of tourists travel to Mongolia not only expecting to see its natural landscape but also to experience its unique, and at the same time, pristine nature, authentic and genuine culture. Most western tourists especially are attracted by the core meaning behind the Mongolian way of nomadic life, the daily activities, and authentic narrative and story of the nomad herders.

National parks are also key attractions to both domestic and foreign travelers. The Gorkhi-Terelj National Park (GTNP) is $100 \mathrm{~km}$ from the capital city, which is under the jurisdiction of the Khan-Khentii Strictly Protected Area (KKSPA). The National Park is one of the traditional tourist destinations in Mongolia, since also the socialist era, 50 percent of domestic travelers (around 500,000 Mongolians) and $1 / 3$ of all foreign tourists coming to Mongolia visit GTNP.

\section{Problem Statement}

Although national parks are top tourist attractions in Mongolia, the overall tourism development concept regarding National Parks has not been finally defined. Issues and challenges that we have come across at GTNP are not only special problems of the area, rather they are very common problems as well throughout the country.

One of the practical significance of this study are the scale and scope of the subject, and also the fact that the issues are not restricted only to GTNP, but are also in fact the challenges being encountered by Mongolia's industry, such as promoting sustainable and efficient stakeholder collaboration, and determining the model of joint management that would help empower and increase the role and participation of the given local people in this management.

GTNP faces several challenges; especially this is becoming increasingly evident today. Besides the socialist era, the initial stage of tourism sector began developing in new freemarket Mongolia in 1990-2000, when international tourism picked up pace. The number of players in the industry started growing - companies and individuals, interested in establishing small scale tourist business in GTNP, such as provision of accommodation and catering, as well as packaged and tailor-made tourl services, such as horse/camel riding, increased in number. The 
overall objective was solely to increase the number of tourists, while the capacity at the end destination was simply overlooked. Therefore, the early stage of tourism in present-day Mongolia was a kind of 'wheel' of integration among these stakeholders.

Today, thankfully the situation has changed, which brought to light a number of challenges, which are outlined below.

The GTNP did not chart out a clear tourism policy and strategy at the local level by stakeholders; therefore, the overall roadmap of the destination is unclear. There has been a lack of management and planning, especially on land use management, which embraces zoning, site planning, and land permission based on the land's carrying capacity. This leads to another challenge, which deprives local stakeholders of pastoral land use. In the early 1990's, the Mongolian government gave to private ownership the country's livestock to the nomad herders. But the ownership over pasture lands and wells, which are an essential and inherent part of the nomadic economic and social life, was left as a muted issue. Nomads have much interest in increasing their animal population, mainly goats, an important source of revenue from the cashmere that goats produce. Therefore, individual herders and the herding community as such are entering into conflict against each other with regard to land use and management, including access to sources of water, the imbalance in the herd structure (too many goats as compared to other commodity animals). Gradually overcrowding has become a new issue at the National Parks where local people (nomadic and semi-nomadic), tourist business owners and employees, domestic and international visitors need to benefit from the

\section{MATERIALS AND METHODS}

For this research both quantitative and qualitative data are needed. According to Jennings 'A mixed approach utilizes aspects from both qualitative and quantitative methodologies, but there will be a predominant use of one methodology over the other' [10]. Therefore, the mixed approach has been used in this study. On the one hand, the research will environmental resources offered at the National Park.

Newly established tourist camps and resorts just want to build more luxurious and comfortable buildings and facilities to satisfy the taste and needs of Asian travelers (Chinese, Korean) and domestic tourists. GTNP's location, close to the capital city, is also one of the reasons why there are new cement block development inside the National Park rather than eco-friendly construction. Initially, local people saw in tourism a bridge to new developments, buildings and equipment, modern civilization and were fascinated by the modern techniques and services. Tourism for the herders became an additional source of income. But today, all above mentioned problems have become a pressure on the local community, making them think twice about "over development" and the misleading belief that tourism can actually benefit their livelihood. Finally, empowerment of local people by other stakeholders is missing, especially in the decision-making process at the National park, although, local people are seen as a key partner in outdoor tourist activity.

Therefore, one of the tasks of tourism development in Mongolia is to re-identify appropriate local inhabitants and stakeholders, who are the key carriers of local nomadic identity and to define the tourist sector as a strategic sector that promotes and sustains the livelihood and the peculiarities of especially the local people living in and around the National Park.

The research questions of this paper are as follows: "What is meant by collaboration of key stakeholders in order to support CBT? What does CBT actually mean for the nomadic communities?".

start from collecting quantitative data and statistics, which relate to tourism development in Mongolia and GTNP. These data have been provided by a National Statistics Office and the Mongolian Tourism Association (MTA). On the other hand, this research required qualitative data especially to gain insight into stakeholders with regard to the challenges they 
are and have been encountering. These data were collected in the form of snow ball interviews with the Park Administration and the local herders. Questionnaires, which are quantitative data of this paper, were carried out among the managers of tourist camps, tour operators and the Park Administration. Sampling was done randomly from among the total target group. The questionnaire was conducted among key stakeholders who represented institutional and private sectors, such as:

\section{A. Government sector}

- Staff of the National Park Administration (6 respondents)

\section{B. Private sector:}

- Tourist camps' Staff (36 respondents)

- Tour operators' Staff (22 respondents)

The interview was taken from 25 local herders, including 14 males and 11 females. Twenty per cent of the interviewees have been living temporally at GTNP during the summer in the last 2-4 years, 35 percent of the interviewees have settled down permanently in the NP for almost $6-10$ years now and another 45 percent have been living at the National Park for more than 10 years.

The study was conducted in four phases. It began with a general layer of analysis in order to devise the theoretical framework to measure collaboration. The second phase is the detailed layer that investigates the the status of collaboration with regard to stakeholders in the GTNP. The third is the analysis layer, which attempts to reveal nomadic community identity, its key concept and traditional approach to collaboration. Finally, the last phase is the synthesis layer, which crystallizes transferable recommendations for the successful mechanism of stakeholder collaboration in terms of theoretical and practical levels in the GTNP, Mongolia. The study illustrates in a descriptive manner the process of crystallizing transferable recommendations for sustainable stakeholder collaboration towards communitybased tourism (Table 1).

Table 1. The research methodological set-up

\begin{tabular}{|c|c|c|c|}
\hline $\begin{array}{l}\text { Research } \\
\text { Layers }\end{array}$ & Research focus & Methodology & Research Methods \\
\hline $\begin{array}{l}\text { Phase A: } \\
\text { General } \\
\text { Layer }\end{array}$ & $\begin{array}{l}\text { Devise } \\
\text { Theoretical } \\
\text { Model }\end{array}$ & $\begin{array}{l}\text { Theoretical Model of Stakeholder Collaboration: } \\
\text { defining stakeholder management, community } \\
\text { participation, collaborative theory and planning } \\
\text { management, concluding stakeholder } \\
\text { collaborative circuit on community-based } \\
\text { tourism }\end{array}$ & - Literature review \\
\hline $\begin{array}{l}\text { Phase B: } \\
\text { Detail } \\
\text { Layer }\end{array}$ & $\begin{array}{l}\text { Investigation: } \\
\text { GTNP, } \\
\text { Mongolia }\end{array}$ & $\begin{array}{l}\text { Investigation of stakeholder collaboration in } \\
\text { GTNP: defining key stakeholders, collaboration } \\
\text { situation between certain stakeholder situations, } \\
\text { level of stakeholders, specificr problems among } \\
\text { certain stakeholders } \\
\text { - Limitations, and } \\
\text { - Opportunities }\end{array}$ & $\begin{array}{l}\text { - Document study on Tourism in } \\
\text { Mongolia and GTNP. } \\
\text { - In-depth stakeholder } \\
\text { Interview } \\
\text { - Three questionnaires: TO, PA, } \\
\text { TC. } \\
\text { - Investigation primary and } \\
\text { secondary data }\end{array}$ \\
\hline $\begin{array}{l}\text { Phase C: } \\
\text { Analysis } \\
\text { Layer }\end{array}$ & $\begin{array}{l}\text { System Analysis } \\
\text { on the nomadic } \\
\text { community and } \\
\text { stakeholder }\end{array}$ & $\begin{array}{l}\text { Comparable analysis between western and } \\
\text { nomadic community saliencies: functionalism, } \\
\text { operationalisation, society identity and local } \\
\text { community at GTNP }\end{array}$ & $\begin{array}{l}\text { - Literature review } \\
\text { - In depth interview } \\
\text { - Snowball meetings } \\
\text { - Document study }\end{array}$ \\
\hline $\begin{array}{l}\text { Phase D: } \\
\text { Synthesis } \\
\text { Layer }\end{array}$ & $\begin{array}{l}\text { Solutions: } \\
\text { Recommendatio } \\
\text { ns and advice }\end{array}$ & $\begin{array}{l}\text { Reconcilements against hampering factors of } \\
\text { stakeholder collaboration towards community } \\
\text { based tourism. } \\
\text { Crystallizes transferable recommendations on } \\
\text { theory and practice }\end{array}$ & $\begin{array}{l}\text { - Literature review } \\
\text { - in-depth stakeholder } \\
\text { interviews } \\
\text { - Document study } \\
\text { - Investigation of primary and } \\
\text { secondary data }\end{array}$ \\
\hline
\end{tabular}




\section{Theoretical background}

Stakeholder Approach Management: The word "stakeholder" is defined in the Oxford dictionary as "a person who holds the stake or stakes in a bet"; the current definition is "a person with an interest or concern in something" [9]. In the context of natural resource management, however, Röling and Wagemakers [12] offer a better, appropriate definition: "Stakeholders are ...natural resource users and managers." In colloquial language other terms are used interchangeably with stakeholder, but with a slightly different connotation. For example, systems analysts refer "stakeholder" to an "actor" and as "a person who carries out one or more of the activities in the system" [11]; sociologists talk about "social actors" as individuals or social entities who are knowledgeable and capable and can thus formulate and defend decisions. One article [8] lists 27 definitions of "stakeholder" in the business literature, and many more are proposed in natural resource management fields. What is relevant here is that modern uses of the term are not synonymous with persons or individuals only, but also refer to groups and organizations that have an interest or are active players in a system. Therefore, it is quite interesting to find who or what can be stakeholders in Mongolia in a society system, which has a nomadic community where tourism and global perspective penetrates.

Once the relevant stakeholders are identified, analysis or differentiation could be determined. Many authors suggest "differentiation" as a basis for appropriate management strategies [15]. In a practical sense, all are not equal-so it is incumbent for management of an organization to prioritize them and focus their efforts accordingly. This prioritization requires a basis for analysis. While different authors have different analytical perspectives, all seek to assess the relationship of the stakeholder to the organization in question.

Sautter and Leisen pointed out [13], that "the fundamental basis of the stakeholder theory is normative. It redefines an organization as a 'stakeholder interest' co-ordinating and optimizing entity," which requires the firm to accept two key concepts: First, Stakeholders are persons or groups with legitimate interests in procedural and/or substantive aspects of corporate activity. Stakeholders are identified by their interests in the corporation, whether the corporation has any corresponding functional interest in them or not. Second, the interests of all stakeholders are of intrinsic value. That is, each group of stakeholder merits consideration for its own sake and not merely because of its ability to further the interests of some other group, such as the shareowner".

From the stakeholder collaboration point of view, it must proactively seek inputs from all groups, as some will have stronger "voices" than others and this should not determine the priority of management's attention. Under this philosophy, the entire purpose of the body (in our case, the National Park destination) becomes the co-ordination of stakeholder interests. Indeed, researchers argue that its overall managerial worth stems from the fact that the normative, descriptive, and instrumental aspects of the theory are "mutually supportive" [13]. Arguably, however, the theory's dominant role is its ability to provide moral and philosophical guidelines for the management of an organization [1]. From a managerial perspective, the stakeholder theory posits that the various groups can and should have a direct influence on managerial decisionmaking [4].

\section{Community and Collaboration Management}

Dependence is the key to collaborate various stakeholders, and it can be seen as the source of power that the stakeholders can wield, hence, having the potential to threaten the organization by withholding resources.

Of course, the objective of collaboration, especially the exchange between stakeholders' power/resources (such as lobby, funds, equipment, and information) into mutually agreeable and achievable passion is instrumental.

In terms of etymology, cooperation as "working together to the same end" and collaboration as "working jointly with" [9] are clearly closely related. Wood and Gray [18] describe collaboration as "...a group of autonomous stakeholders of a problem domain 
Tourism and communities link up in

engaged in an interactive process, using shared rules, norms, and structures to act or decide on issues related to that domain'. Generally, collaborators are not completely autonomous, but rather that collaborative efforts between two organizations are conditional on recognition of interdependence, on an agreement that the issue is important, and in the belief that significant benefits will be derived from addressing it.

The study of community is broadly discussed in various sociology works, especially on rural studies. Ashton maintains that there are at least 90 definitions of 'community 'in sociology science. Koelen and Van den Ban [6] argue that among all these numerous definitions, two broad lines can be distinguished, that is, 1) definitions in terms of geographical area and 2) definitions in terms of shared characteristics.

Though the geographical dimension is important, I follow the second line. It refers to the existence of potential resources such as people's skills and knowledge in social networks. In this way, communities are seen as groups of people with common perceptions of needs, interests and priorities, who can express their relationships without difficulty through communication.

Particularly, a community is not static, it is rather dynamic, thus, it is not only a compilation of people but is a social institution which can be communities in their own right. Moreover, it is the cultural identity, which the people have their common shared values together.

Therefore, 'community' as a social phenomenon incorporates four elements: people, meanings, practices, and space/structures. According to Liepins, Communities consist of people and things, which are perpetually being reproduced, sustained, undermined and reconfigured by cultural, political-economic and socioecological processes that have occurred in the past and are still occurring in the present. $[7 ; 2$ : 61] various interactive spaces that are continuous processes in which different social values interact and new meanings are formed [17]. Therefore, GTNP in Mongolia has its own 'community' which consists of its own people, meaning, practice and space/structure. Once, tourism penetrates the local communities in Mongolia, transformation and integration process between communities and tourism are likely to occur. In this sense, the process is complicated and it is also very much dependent on how the characteristics of the communities can be defined. The community characteristic or local circumstances can be limitation or opportunity to this transformation process in the tourism development process. Stakeholder collaboration between community and tourism sector plays quite an important role in ensuring that tourism sector suits the community. Thus, the local community needs to be empowered to decide what forms of tourism facilities and wildlife conservation programs they want to see developed in their respective communities, and how the tourism costs and benefits can be shared among different stakeholders [2].

Based on theoretical exploration of the study, the following model of stakeholder collaboration process (Figure 1) is proposed. This circuit consists of a four-stage process. There is always current situation and clear impact on the domain. This practical situation leads to aspirations and needs to collaborate, because of the interdependence of those stakeholders who are attached with this domain. The first process starts with the identification of relevant stakeholders in the domain. In other words, this means finding out who affects and is affected to/by the domain and what are their interests and priorities. In order to find this, 'four dimensions of sustainability' can be useful in examining the position, stand-point of stakeholders. The outcome of the first process is to establish problem-setting of the stakeholders in the domain. 


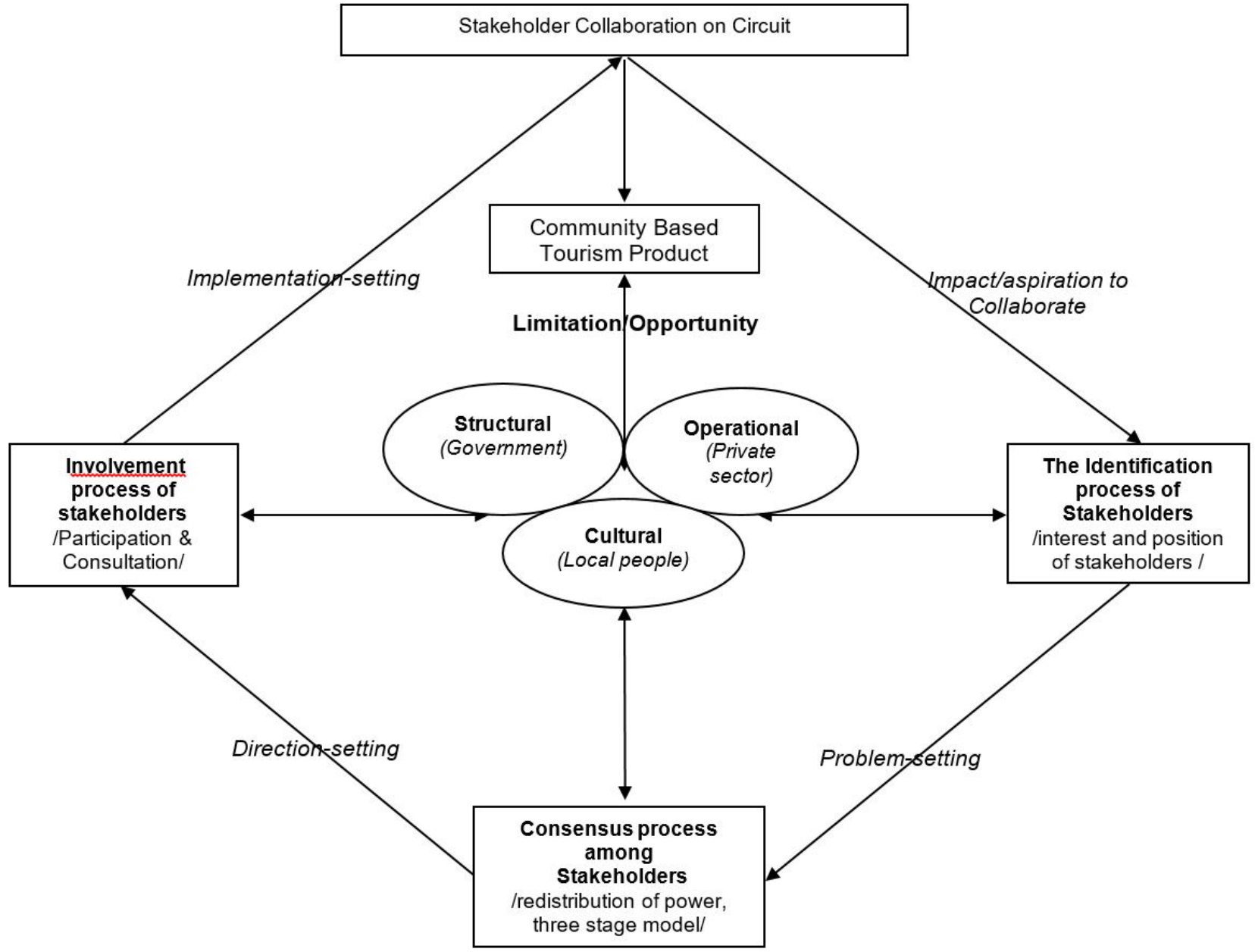

Figure 1. Stakeholder Collaboration Circuit Model

Tourism in the GTNP/stakeholder analysis

According to the analysis, the Park Administration holds the legal authority; tourist camps and operators have market, service and economic powers and the local people control the socio-cultural resources as local know-how. Therefore, all four are to be considered as key stakeholders at GTNP.

Key stakeholders (n-80) think that tourism affects the National Park more negatively $(68 \%)$ than positively $(32 \%)$ (Figure 2)

Figure 2. Effects of tourism on GTNP

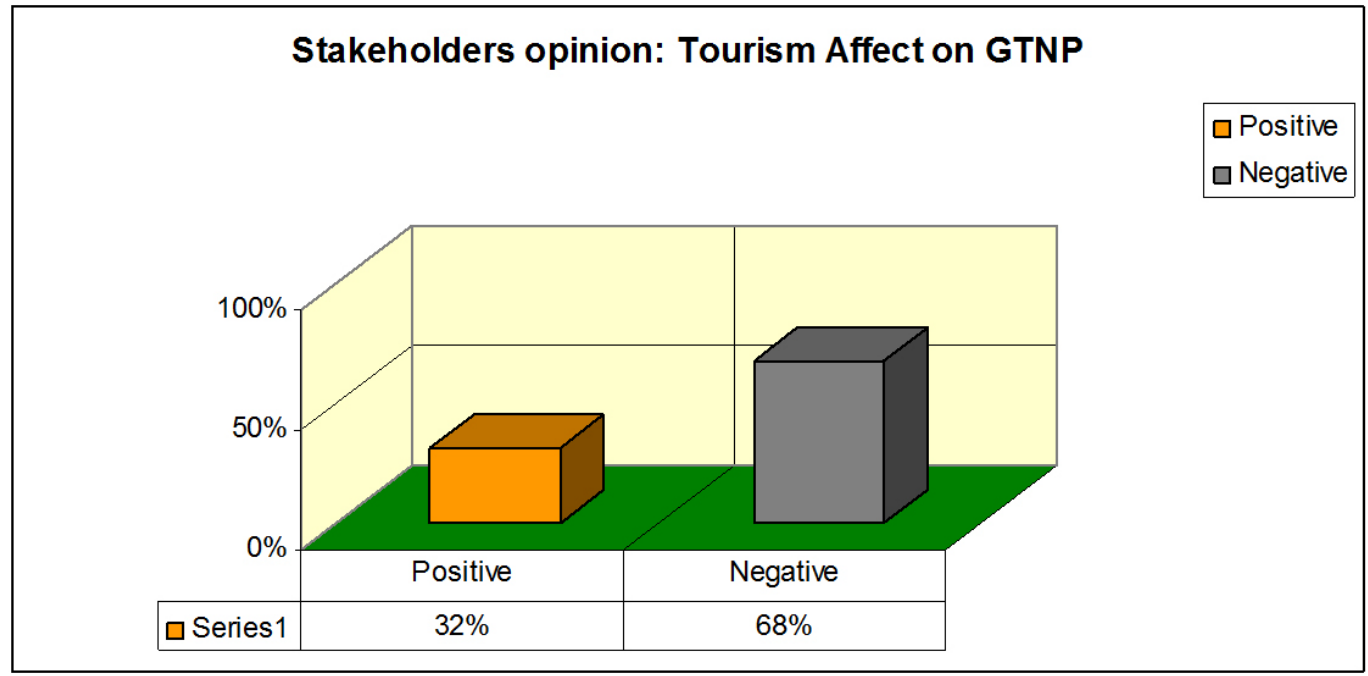


As discussed earlier, stakeholders were satisfied in the beginning but now a lot of problems are becoming clear in GTNP and new conflict situations are emerging among tourism stakeholders and these situations are aggregating. Therefore, according to stakeholders' opinion, the negative impact of tourism is much bigger than the positive one.
Employment is the most significant positive outcome of tourism in GTNP, according to tour operators and tourist camps (n-60). The Park Administration (n-6), on the other hand, thinks that better livelihood and new and better reputation of the NP are the biggest positive effects (Figure 3).

Figure 3. Positive effects of tourism

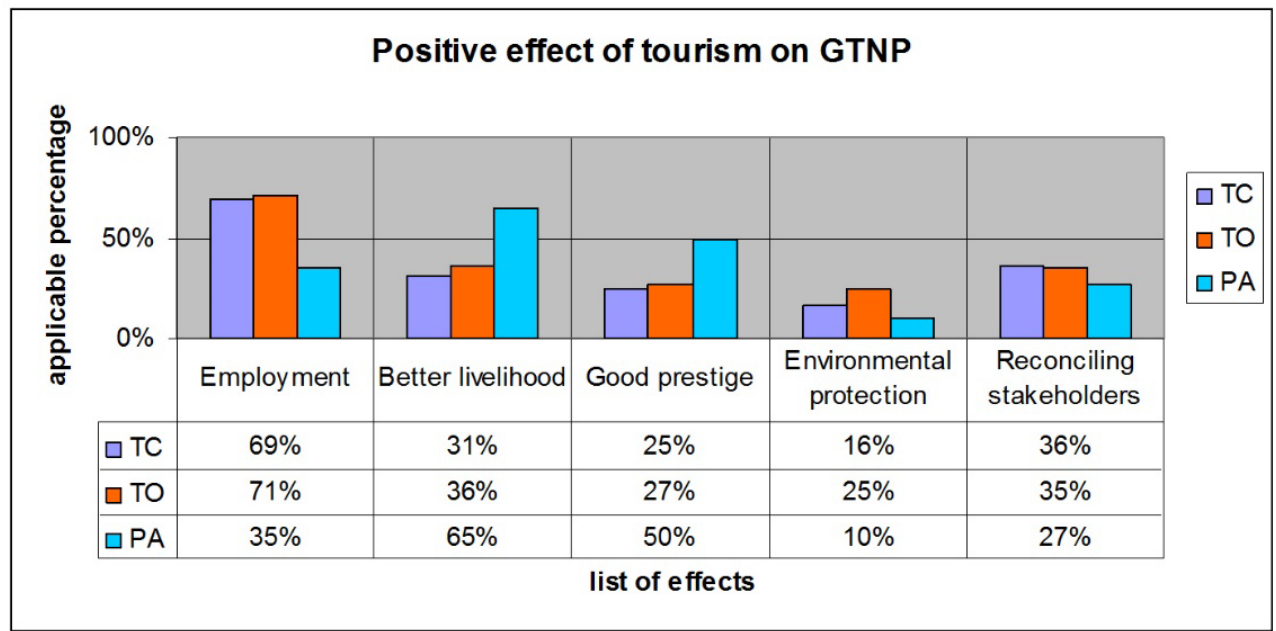

As concerns the negative effects, almost all stakeholders agreed that the problem of pasture overgrazing is critical for everyone. Almost all local people, who were interviewed, were not happy that the pasturel land is used by everyone, such as tourist camps, tour operators, new herders who move into their domain. Most tourist camps $(85 \%)$ raise their own animals (sheep, goats, cows and horses)m which they also use for producing meat, milk and other diary produce. Tourist camps have been growing like mushrooms at GTNP. What's more, vehicles of tour operators (bus, jeep, and minivan) with tourists regularly ply the pasture lands without impunity nor any concern for the environment. Tour operators have been also organizing different itineraries on the pastures. The consequences are the numerous tracks, littering, overgrazed lands and the shrinking of water resources of wells and river. Plus, new herders, who move temporarily in to GTNP, expecting to get some kind of benefit from tourism, such as temporary employment, additional income from domestic and foreign tourists by renting their ger, or making nomadic food and selling souvenirs and so on. Finally, overgrazing is the basic and fundamental issue for each stakeholder and also between them. As discussed in the first chapter, the key elements of nomadic community are land, animal and people. So the land in GTNP is getting overgrazed and disqualified by the transition of the society and the 'onslaught' by the new tourist sector.

Overcrowding of the tourist areas and environmental pollution accelerate the overgrazing problem. For example, tourism camps pay more attention to overcrowding and environmental pollution, because these are considered as significant practical problems for them. It is quite difficult to operate a tourist camp with traditional Mongolian ger in such a way as to provide western facilities and equipments in the wild nature. Thus, environmental issues, one can safely claim, are least pressing for them. Tour operators are unhappy with overcrowding, subsequently they like to open new itineraries far from current crowded areas. On the one hand, nomads are also not very happy with this, because this kind 
of new itinerary development further complicates the overgrazing problem. While on the other hand, tour operators also consider the cultural and social quality of life of local people, because, this is what makes their tour packages attractive. The Park Administration is mostly worried about overcrowding and environmental pollution, which are their primary responsibility [10]. But tourist camps and tour operators see that tourism brings new problems, and that these problems cause conflict among stakeholders. But PA is not really concerned about this issue. This is shown in Figure 4 (n-59).

Figure 4. Negative effects of tourism

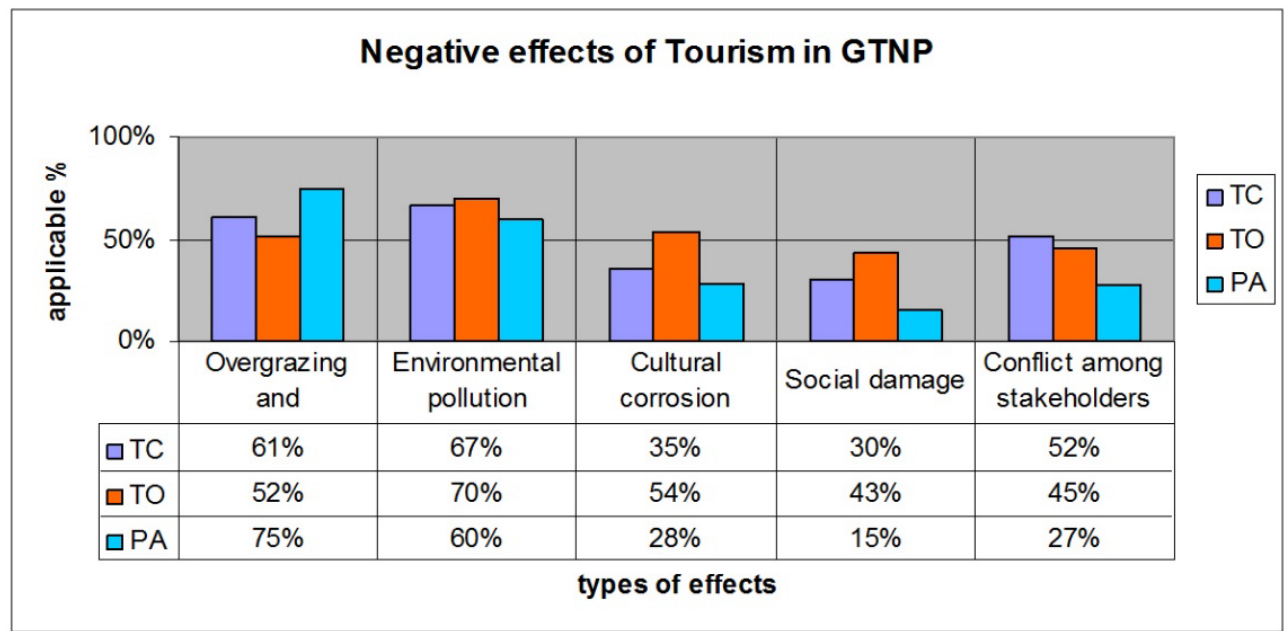

There is no firm and concrete statistic data about how many visitors have been in the National Park, according to official statistics. According to the PA data, 28,377 foreign tourists and 131,245 domestic visitors have entered the GTNP for just an overnight during the holiday season in 2018, while Mongolian Tourism Association has said that the number of visitors to the area has already exceeded half a million [14]. These numbers might be based on entrance fee income, but local people and guards who work at the entrance gate disagree with this figure, as they believe that the figures are much higher than claimed officially. Tour operators prefer to decrease or keep the current number of visitors (68 per cent) instead of increasing it. The number of foreign tourists has been decreasing in the last few years, according to tour operators. Yet, the cost of a package tour offered by tourist camps are still high (27-30 USD per person per day including 3 meals and ger accommodation). Tourist camp managers want to maximize the number ( 45 per cent) of tourists. This is related to the fact that the number of tourist camps have been rapidly increasing in recent years, and many visitors prefer to stay in their own tent or in local people's extra ger. The occupation of beds in the tourist camps used to be $80-100$ per cent during the tourist season, whereas it is now just 40-60 per cent

The survey asked about the current tourist programs in the GTNP. 52 per cent of the tour operators are focused on GTNP as a destination for short programs; therefore, a typical tourism in GTNP is seen as a passive relax tour programs, where tourists are staying in a ger camp and go sightseeing around the camp. At the same time, forty-eight percent of tour operators prefer adventure and active tours with several days of programs including hiking, horse riding, and camping.

For other National Parks, tourist camps are located near unique cultural or natural attractions, but the camps are normally located at god distance from each other. However, in GTNP, tourist camps are closely located in every mountain glen just like tourist hotels and amusement centres on the beach in countries with developed seaside tourism. Thus, all tourist camps form a sort of a contained resort area. This is a quality picture of current tourism. 
Most respondents prefer different types of tours than the current quality of tourism in GTNP as the table below shows (Figure 5, n78). As discussed earlier, most of the visitors who enter the National Park are domestic visitors and it is quite difficult to charge them entrance fee. In this way, the PA is losing its control and seemingly appears to become powerless, which probably is the main reason why PA wants different types of tour programs that can help them reinstate their power and authority.

Figure 5. Assessment of current tourism quality by stakeholders

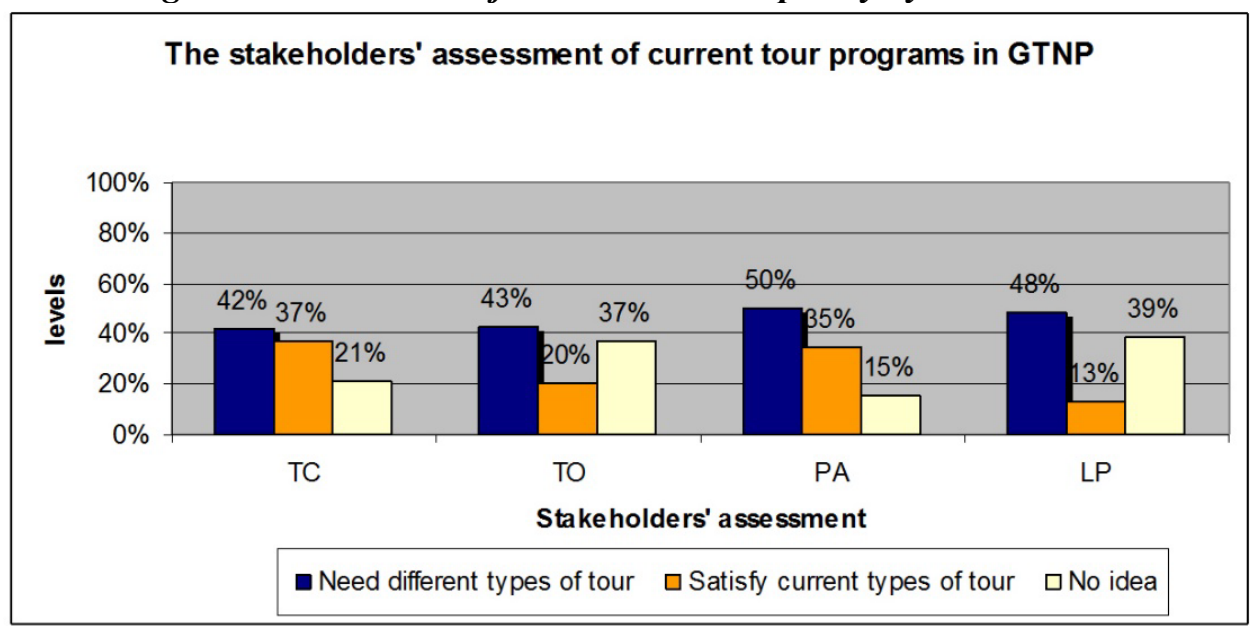

However, all stakeholders are ready to look at multi-tourism programs than the current ones, which are targeted at resort and pleasure tourism. This could be one of the mutual voices to establish a common mission among the stakeholders.

Tourism has already penetrated in to this place; therefore, all stakeholders simply cannot imagine GTNP without the tourism sector. Thus 82 per cent of all stakeholders have stressed the importance of tourism for GTNP development.

\section{Stakeholders' Interest on Collaboration}

To assess the collaboration of key stakeholders, it is important to determine the position of each stakeholder in GTNP. The position of stakeholders is based on their capacity and power in the tourism network. This means which stakeholder holds what stake or in other words, which stakeholder stands on what resource in the tourism sector. In order to analyze this, the "four margins of sustainability" are used here (Figure 6). The functionality and accessibility of stakeholders and the assessment survey of stakeholders regarding the impacts of tourism are the basis for determining the position of stakeholder in one of the four margins.
First of all, almost all international tourists visit the park via tour operators; this means they hold the marketing promotional accessibility and product development. Therefore, the issue of profit in this park depends on the capacity and power situation of the tour operators since the main budget of GTNP, the income of local people and tourist camps, primarily come from international tourists. On the other hand, tour operators are really concerned about the socio-cultural quality of local people for the following reasons. 1) Socio-cultural aspects are quite significant to tourists' satisfaction, so tour operators realize that the cultural attraction, the everyday life of nomadic people are the most significant elements of their current programs. 2) Tour operators also want to establish more cultural and ethnic tour programs based on the life of the nomadic people in GTNP. Therefore, it can be stated that tour operators' position is between profit and socio-cultural margins.

Furthermore, tourist camps are private entrepreneurs in GTNP. Their services, products, hospitality are highly significant for tourism to be profitable in this place. Thus, tourist camps' resources and capacity depend more on the profit margin; this could be their power indeed. On the other hand, tourist camps' 
business depends on environmental quality, in this sense, it is very important to manage tourist camps in an environmental friendly way. Therefore, tourist camps can be placed between profit and ecological margins.

The Park Administration is responsible for all legal and political aspects of the national park development. And its most important function is the ecological aspects of GTNP, according to law. It is reasonable to put PA between risk and ecological aspects.

Local people have a hold on the sociocultural resources and capacities in the collaboration process. Indeed, socio-cultural highlights and identity exist among local people, but on the other hand, local people have liability and rights, responsibility and risks to participate in local level issues. Also the most moral and ethical powers go to the local people. In Mongolia, the official law is not always powerful, but in many cases ethical, cultural and religious values determine practical communication in the society. This is the basis for positioning local people between sociocultural and risk margins.

Based on the above reasons, it is possible to locate the position of the key stakeholders according to the four margins as follows (Figure 6):

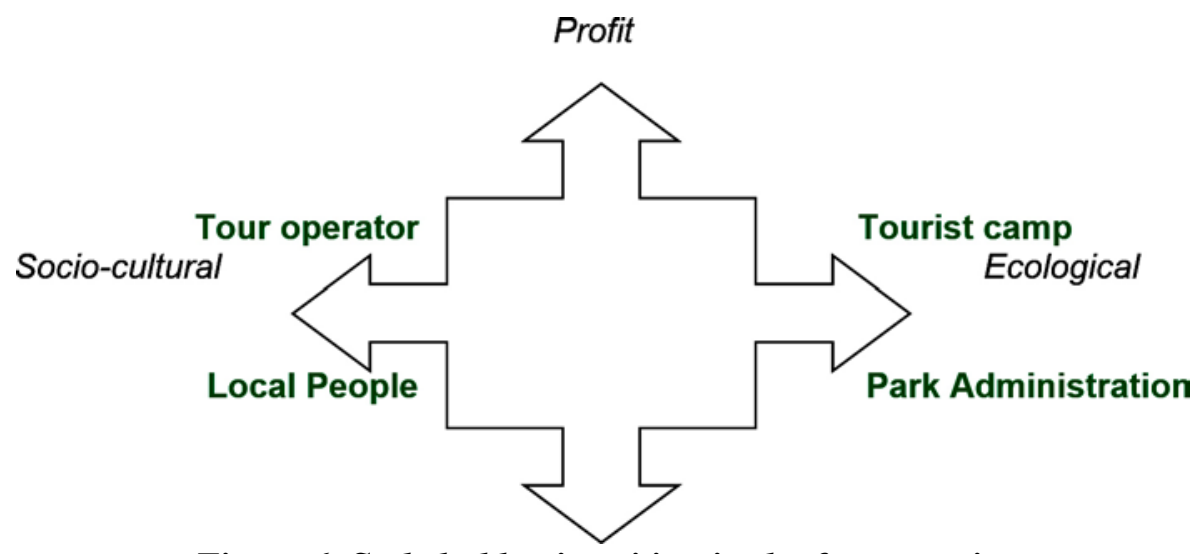

Figure 6. Stakeholders' position in the four margins

It is quite handy to find the interest and resource of the key stakeholders, because, on the one hand, stakeholders participate, as much as possible, in tourism collaboration from their point of view, and on the other hand, it is important to know where are the problems, and

\section{RESULTS AND DISCUSSION}

This study has been produced for the purpose of furthering the debate on the importance of cultural identities in sustainable development processes. First of all, I have introduced an appropriative collaboration system among local key stakeholders towards community-based tourism based on the combination between western theoretical approaches and local community characteristics in the Gorkhi-Terelj National Park (GTNP), Mongolia.

In order to accomplish research objectives, key stakeholders of sustainable how to solve them and through which resources. This can be the main advantage of the collaboration between stakeholders if they encourage each other's activity to reach a common vision and to find a solution for their problems by sharing each others capacities.

tourism in the national parks have been identified, and the reasons hampering sustainable collaboration between these stakeholders have been analysed.

The local circumstances of the community towards supportive collaboration were analysed on three levels of limitations: operational, structural and cultural. The overall factors of tourism hampering stakeholder collaboration towards community-based tourism at GTNP are the non-appropriative system for stakeholders' collaboration, political dependency at the local level, one-sided and 
unclear policy and planning, absence of clearcut guidelines on management strategy, lack of reinforcement of supportive legislation, lack of experts in the tourism sector and lack of accessibility of local people to decisionmaking. Particularly, local socio-cultural identity system at the GTNP community, which is seen as an opportunity to build up successful stakeholder collaboration, has been analysed: the state of mind, such as "togetherness and interdependence" of the Mongolian people; mobile but collaborative groups of nomadic community: ail (Camp of one herder household), khot ail (camp of several different herder households) and neg goliihon (meaning from the same place or locality); cultural and religious ramification, such as local song, local festival, locally- worshipped mountain etcetra.

To improve stakeholders' collaboration towards community-based tourism, this research proposes a "Three Layer Collaboration System for Pasture-based Tourism Stakeholder Groups" which is the mixed approach between western principles and nomadic community traditions.

Especially given the fact that tourism plays a critical role by positively and negatively impacing on both local cultural identity and sustainable development. Thus, as the next output of this research, let me ask how tourism, especially a community-based tourism (CBT), could enforce local culture, a key identity of the local people towards sustainable development? Yet, CBT is a kind of approach to achieving sustainable tourism development, which is also grounded on local circumstances. In other words, local cultural identity enriches, specifies the CBT approach by the way of matching between local cultural identity and tourism development. In this study I propose " $A$ nomadic friendly tourism", or "Nomadic tourism" as a practical tool that conserves both the natural and cultural landscape of the Mongols.

In the Mongolian tourism sector, it is important to strengthen the participation of nomadic people in the tourism supply chain process, rather than merely appreciating the role of local people in the tourism sector. More specifically, how and to what extent should we remain passive onlookers to see how tourism will not destroy or less negatively effect on the identity of local people and their lifestyle, even if it is simply CBT. However, CBT is quite a complicated matter, because it is not just how to involve local people in the tourism business, rather how tourism can be a development strategy, which can empower the community's needs based on its identity resources.

Mongolian tourism resources are directly associated with the local people, their local knowledge and assistance in order to provide what tour operators have promised to their clients. It makes an inter-dependable cooperative circumstance between tour operators and nomadic people in order to package tour products that can be viable and acceptable to the western market, mostly. Tour operators hold the marketing promotional accessibility and product development, while the local people have a hold on the sociocultural resources and capacities in the collaboration process.

A nomadic-based tourism is a practical tool that conserves the natural and cultural landscape of Mongolia. A set of principles of how to implement tourism where the approach is to understand the livelihood of local nomadic people, in order to bring a local value for cultural preservation and maintenance, as well as additional income to the community.

Based on this study, I could argue that although economic and ecological benefit of tourism is an important component of the community-based tourism, the empowerment of nomadic culture is the most critical element for achieving a successful nomad-based tourism development in Mongolia.

Through strengthened nomadic people's tradition and culture, herder communities have developed their own appropriate sustainable social fabrics. And nomad-based tourism is not only nomad supportive tour services, which can be provided in different sales channels, rather it is a management and ownership model, a collaboration system of how herder people are involved in the tourism value chain process. 
The key elements of the GTNP community are pastoral land, animals and people. Thus, it is essential that the tourism sector becomes integrated in these key concepts of the community. In order to do that, tourismrelated stakeholders (tour operators and tourist camps) have to adjust their activity with the local community. For example, it is important to reveal all possibilities and capacities of local people, and to maintain them so they fit their needs and requirements.

The main point of this study is that the key stakeholders have to (re)establish an integrated community system between tourism and local nomadic life based on respect for key identities of traditional local community such as people, land and animals.

The remarkable thing is that Mongolian nomads have several thousand years of experience on how to live together with nature in an environmentally friendly way, and to keep their own unique culture, pastoral lands and social value system. So the main message here

\section{REFERENCES}

1. Donaldson, T., and L. Preston (1995). The Stakeholder Theory of the Corporation: Concepts, Evidence, and Implications. Academy of Management Review 20: pp. 65-91.

2. Duim, V.R van der. (2005). Tourisms capes an actor-network perspective on sustainable tourism development Dissertation Wageningen University. Pp. 61-65.

3. Goodwin, Harold \& Rosa Scintilla. (2009). Community-Based Tourism: a success? Occasional Paper No.11, ICRT.

4. Jones, T. (1995). Instrumental Stakeholder Theory: A Synthesis of Ethics and Economics, Academy of Management Review 20: pp.404-437.

5. International Tourism Highlights. (2019) Edition.

6. Koelen, A. Maria and Anne W. van den Ban (2004). Health Education and health promotion, Wageningen Academic publishers. p.136. is that the key issue of successful collaboration between stakeholders in GTNP is to (re)define an accepted norm of behaviour and engagement with the community and mobile stakeholder or stakeholder group, which adjusts with the local community system comprising of land, people and animals.

Acknowledgement This research was supported by Khan Khentii Strictly Protected Area Administration, Mongolian Tourism Association and my supervisor Rene van der Duim (Ph.D), practitioner Jan Wigsten and Mongolian tourist companies, such as Active and Adventure Tours Mongolia LLC, especially local people groups such as Baruun and Zuun Bayants. My special thanks to academician G. Chuluunbaatar, Mongolian Academy of Sciences and M. Zolzaya, Mongolian Philosophical Association who supported me by providing theoretical insight and experiences, which have made possible this study.

7. Liepins. R. (2000). Exploring rurality through "community" discourses, practices and spaces_shaping Australian and New Zealand rural "communities". //Journal of Rural Studies 16, 325 (34).

8. Mitchell, R., B. Agle, and D. Wood (1997). Toward a Theory of Stakeholder Identification and Salience: Defining the Principle of Who and What Really Counts. Academy of Management Review 22: pp. 853-886.

9. Oxford Dictionary, (1982). pp. 182, 208

10. Jennings, G. (2001). Tourism Research, John Wiley and Sons Australia, Ltd.

11. Peter Checkland, (1981). Systems Thinking, Systems Practice. Wiley, p. 26.

12. Röling, N., Wagemakers, M., ed. (1998). Facilitating sustainable agriculture: participatory learning and adaptive management in times of environmental uncertainty. Cambridge University Press, Cambridge, UK. p.152. 
13. Sautter, E., B. Leisen (1999). Managing Stakeholders: A Tourism Planning Model. Annals of Tourism Research 26: pp.312328.

14. Social and Economic Situation of Mongolia (As of the preliminary result of 2019). National Statistics office of Mongolia. Integrated Statical Database. Published at: 2019 / 12 / 12. 10: 53. Park Administration Report, KKSPA, Annual Report, 2019.

15. Starik, M. (1994). The Toronto Conference: Reflections on Stakeholder
Theory. Business \&Society 33 (1): pp. 8995.

16. The report of GTNPA, 2004.

17. Wearing, S., and M. McDonald (2002). The Development of Community-Based Tourism: Re-thinking the Relationship between Tour Operators and Development Agents as Intermediaries in Rural and Isolated Area Communities. Journal of Sustainable Tourism 10: pp.191-206.

18. Wood, D, and Gray B. (1991). Toward a Comprehensive Theory of Collaboration. Journal of Applied Behavioural Science 27: pp.139-162. 